\title{
EFEITOS DA INTERVENÇÃO PRECOCE NO DESENVOLVIMENTO DE UMA CRIANÇA COM TEA: INTERFACE ENTRE NEUROCIÊNCIAS E EDUCAÇÃO
}

\author{
Karla Osiris Freire Leal Viana ${ }^{1 *}$ \& Sulamita da Silva Nascimento ${ }^{1}$
}

\section{RESUMO}

VIANA, K.O.F.L.; NASCIMENTO, S.S. Efeitos da intervençao precoce no desenvolvimento de uma criança com TEA: interface entre neurociências e educação. Perspectivas Online: Humanas \& Sociais Aplicadas, v.11, n.30, p.38-50, 2021.

A pesquisa teve como objetivo comprovar que a intervenção precoce potencializa $o$ desenvolvimento de uma criança com TEA e contribui para um melhor prognóstico. $\mathrm{O}$ interesse na abordagem sobre o tema surgiu da necessidade de mostrar que o diagnóstico e tratamento precoces, fundamentados cientificamente, potencializam as chances de remissão das disfunções decorrentes dessa condição. Trata-se de um estudo de caso, de natureza qualitativa, exploratória e descritiva. Utilizou-se de estratégias de intervenção diversificadas, observação clínica, entrevistas e instrumentos avaliativos validados. Os resultados apontaram avanços significativos nas respostas aos estímulos sensoriais, interação, imitação e linguagem. Os processos de intervenção e investigação ocorreram simultaneamente, buscando-se caracterizar o diagnóstico. Percebeu-se que a intervenção precoce é uma estratégia eficiente, com a propriedade de ampliar as conexões neurais, como afirmam os estudos da Neurociência.

Palavras-chave: Transtorno do Espectro Autista, intervenção precoce, neuroplasticidade, neurociência. 


\title{
EFFECTS OF EARLY INTERVENTION IN THE DEVELOPMENT OF CHILDREN WITH AUTISM SPECTRUM DISORDER: AN INTERFACE BETWEEN NEUROSCIENCE AND EDUCATION
}

\begin{abstract}
This research had as an objective to prove that early intervention potentializes the development of children with ASD (Autism Spectrum Disorder), and contributes to a better prognostic. The interest in this approach to the theme originated from the necessity to show that early diagnosis and treatment, scientifically fundamented, potentialize the odds of the remission of the dysfunctions associated with the disorder. This is a case study, of a qualitative nature, exploratory and descriptive. A plethora of intervention

strategies were used, such as clinical observation, interviews and validated evaluative instruments. The results point to significant advances in the response to sensory stimuli, interaction, mimicry and language. The intervention and investigation processes occurred simultaneously, in search of a characterization of the diagnosis. It was apparent that early intervention is an effective strategy, with the properties of amplifying neural connections, as confirmed in studies in Neuroscience
\end{abstract}

Keywords: Autism spectrum disorder, early intervention, neuroplasticity, neuroscience.

\footnotetext{
${ }^{1}$ Institutos Superiores de Ensino do CENSA - ISECENSA - Laboratório de Formação de Professores - LAFORP NUPED/ISECENSA - Rua Salvador Correa, 139, Centro, Campos dos Goytacazes, RJ, CEP: 28035-310, Brasil. $(*)$ e-mail: karlafreireise@gmail.com

Data de recebimento: 23/01/2021. Aceito para publicação: 12/03/2021. Data da publicação:14/04/2021
}

Persp. Online: hum \& sociais aplicada., Campos dos Goytacazes, 30 (11)38-50- 2021 seer.perspectivasonline.com.br 


\section{INTRODUÇÃO}

O transtorno do espectro autista ainda se apresenta como um grande "mistério". Muitos estudos revelam avanços na compreensão do TEA e ajudam no olhar para a importância da intervenção precoce ao se detectar os primeiros sinais e sintomas que podem surgir desde a mais tenra idade. A literatura aponta que ainda que o diagnóstico seja um processo detalhado, meticuloso e, em alguns casos, moroso, deve-se intervir com vistas a um melhor prognóstico. $\mathrm{O}$ aprofundamento em leituras e pesquisas tem possibilitado o entendimento de que o transtorno possui uma gradação e de que cada criança manifesta alguns sinais e outras não. Cada uma é singular, tem a sua própria forma de ver e entender o mundo.

Riesgo (2016, p. 412), afirma que diversos são graus de comprometimento nas crianças com TEA, "na medida em que a cognição e a linguagem não são muito atingidas, melhora o prognóstico, no que se refere às potencialidades para o aprendizado". Ressalta ainda que um importante fator de prognóstico se apresenta por meio do potencial cognitivo.

As dificuldades podem ser minimizadas se forem detectadas precocemente e, assim que forem descobertas, se iniciem as intervenções. Para Cosenza e Guerra (2011, p. 135), o diagnóstico e intervenção precoce indicam uma estratégia efetiva em muitas crianças, possibilitando a uma qualidade de vida. Os autores afirmam que "as intervenções educacionais, comportamentais e fonoaudiológicas são as mais importantes e visam o desenvolvimento social e cognitivo, as comunicações verbal e não verbal, a capacidade de adaptação e a solução de comportamentos indesejáveis". A remissão de sintomas ocorre com a evolução cognitiva da criança, ainda que o autismo não tenha cura.

A importância da intervenção precoce, nos casos de TEA, conduz o pensar sobre a importância do estudo da Neurociência para a compreensão da evolução cognitiva na perspectiva da neuroplasticidade. A neuroplasticidade pode ser definida como a capacidade de o sistema nervoso alterar sua estrutura e sua função. $O$ cérebro humano, assim, é capaz de se reestruturar em função de novas exigências ambientais (SALES, 2013 apud OHY, 2018).

Rotta (2016, p. 413), ressalta que "plasticidade cerebral e aprendizado são palavraschave da sobrevivência de todos os animais. No caso das crianças, é um fenômeno importantíssimo, tanto no aprendizado quanto na recuperação de lesões precoces, ou seja, no "reaprendizado"”.

Compreender a aprendizagem sob o ponto de vista da Neurociência é entender que "quando um estímulo é conhecido desencadeia lembrança; quando um estímulo é novo, desencadeia uma mudança" (RELVAS, 2015, p. 17). É justamente num conjunto de estratégias diversificadas de intervenção, que reside a possibilidade de transformação comportamental, da linguagem, das respostas sensoriais e das habilidades sociais.

O Quadro 1 apresenta as habilidades adquiridas durante o período considerado como crítico (DOHERTY, 1997 apud BARTOSZECK, BARTOSZECK, 2007).

Persp. Online: hum \& sociais aplicada., Campos dos Goytacazes, 30 (11)38-50- 2021 
Quadro 1: Habilidades adquiridas durante o período crítico

\begin{tabular}{|c|c|}
\hline Funções & Faixa de desenvolvimento \\
\hline Visão & Do nascimento até os seis anos \\
\hline Controle emocional & Dos nove meses aos seis anos \\
\hline Linguagem & Dos nove meses aos oito anos \\
\hline Habilidades Sociais & Dos quatro anos aos oito anos \\
\hline Música & Dos quatro anos aos 11 anos \\
\hline Segundo idioma & Dos 18 meses aos 11 anos \\
\hline
\end{tabular}

Fonte: BARTOSZECK, BARTOSZECK, 2007.

Ohy (2018, p. 28-29) explica que o período crítico, também denominado de janelas das oportunidades, compreende o período mais importante para o desenvolvimento de habilidades fundamentais. O que se aprende nesta faixa etária acompanha a criança por toda vida.

Rotta (2016) afirma que só entre os 3 e aos 5 anos de idade ocorre maior impulso sinaptogênico na porção média da corticalidade pré-frontal. Área em que as crianças com TEA apresentam maior prejuízo e é fundamental para o desenvolvimento da linguagem, da atenção, da memória de trabalho, da flexibilidade cognitiva, do controle inibitório. É então, nesta etapa da vida, que se deve atuar com intensidade de estímulos, a fim de provocar o desenvolvimento destas funções mentais superiores.

Pantano e Zorzi (2009 apud DIAS; PESSANHA; NICOLAU, 2018, p. 27-29) ressaltam que "a atenção faz com que haja a percepção de alguns estímulos e a negligência de outros dentro do processo cognitivo. Atenção e memória formam, assim, uma via de mão dupla em que um é dependente do outro para a seleção dos estímulos e para o seu armazenamento".

Por ser um fenômeno comprovadamente neurológico, a memória depende da eficiência que diferentes redes neurais interagem durante os processos de reestruturação neuroplástica. Tal eficiência pode ser induzida através de técnicas não invasivas de estimulação cerebral, como as batidas binaurais, que é um modelo eficientemente apto a fornecer modificações nos modelos corticais e na execução durante o trabalho do encéfalo. Esta possibilidade viabiliza o aperfeiçoamento da produtividade na função cognitiva, abrindo espaço para a plasticidade do cérebro, o que beneficia o desempenho cognitivo a partir da organização de distúrbios apresentados nos mecanismos atencionais (MACEDO et al. 2010 apud CALOMENI et al. 2018, p. 28).

Numa abordagem neurobiológica da aprendizagem há um entrelaçamento entre as áreas de educação e saúde. É nesse diálogo interdisciplinar e na visão multidisciplinar que ocorrem os eventos cognitivos. Riesgo (2016) compreende ser possível a interface entre o profissional da educação (educadores, orientadores educacionais, pedagogos e psicopedagogos) e da saúde (pediatras, neurologistas, neuropediatras, psicólogos, psiquiatras da infância e adolescência, fonoaudiólogos, psicomotricistas, fisioterapeutas e terapeutas ocupacionais, entre outros).

A contribuição das Neurociências à educação, a neuroeducação, por meio de estudos e pesquisas, indicam também a possibilidade de se conhecer o funcionamento cerebral, as diferentes áreas para uma melhor compreensão do como se dá o processo de aprendizagem, quais são as propostas mais assertivas. Para Relvas (2017, p. 146), por meio da Neurociência pode-se "explicar, modelar e descrever os mecanismos neuronais que sustentam os atos

Persp. Online: hum \& sociais aplicada., Campos dos Goytacazes, 30 (11)38-50- 2021 seer.perspectivasonline.com.br 
perceptivos, cognitivos ou motores, disponibilizando os fundamentos necessários à orientação da aprendizagem".

$\mathrm{Na}$ esteira desse pensamento, Riesgo (2016, p. 9) argumenta que estudos e pesquisas provenientes das Neurociências e da área médica, em especial da neurologia, são de profunda relevância para a compreensão de todo o "processo de aprendizagem e dos seus distúrbios, que, em última análise, são funções neurocognitivas, também denominadas funções corticais". Tem-se, portanto, a construção de novos paradigmas a partir das bases neurobiológicas do aprender. Entende-se, dessa forma, a importância da prevenção, do diagnóstico e intervenção precoce sob as duas perspectivas: educacional e clínica. A tríade: olhar preventivo, intervenção e diagnóstico precoce, contribuem para um prognóstico positivo do desenvolvimento de crianças com TEA.

\section{Autismo: uma viagem pelo espectro}

O autismo é um transtorno do Neurodesenvolvimento caracterizado por uma díade: déficit persistente na comunicação social recíproca e na interação social e padrões restritos e repetitivos de comportamento, interesses e atividades (DSM-5, 2015, p. 50-53), manifestando-se desde os primeiros anos de vida.

O termo autismo origina-se do grego autós, que significa 'de si mesmo', tendo sido utilizado pela primeira vez pelo psiquiatra suíço E. Bleuler, em 1911, que procurava delinear o processo de "fuga da realidade e o retraimento interior dos pacientes acometidos de esquizofrenia" (CUNHA, 2017, p. 20).

De acordo com Whitman (2015, p. 22-23), “a maior parte das histórias de autismo se inicia apenas nos anos 1940, com o trabalho de Leo Kanner, psiquiatra infantil, que publicou um artigo descrevendo um novo transtorno, o autismo infantil”.

Segundo Cunha (2017, p. 20-21), a primeiras publicações de estudos e pesquisa sobre o autismo, ocorrem em 1943, de autoria de Kanner, que "constatou uma nova síndrome na psiquiatria infantil denominada, a princípio, de distúrbio autístico do contato afetivo".

Para Teixeira (2016, p.24), a nova classificação uniformiza o diagnóstico pois cada caso envolve uma miscelânea de sintomas e manifestações muito diferentes e distintos uns dos outros, mas com características básicas comuns que os tornam a mesma patologia dentro de um espectro que vai de quadros mais leves a mais graves.

O DSM-5 (2015, p. 52), especifica os níveis de gravidade do Transtorno do Espectro Autista na díade: Comunicação Social e Comportamentos restritos e repetitivos em: nível 1 "exigindo apoio"; nível 2 - "exigindo apoio substancial" e nível 3 - "exigindo muito apoio substancial", considerando nível 1 leve, nível 2 moderado e nível 3 grave.

Silva (2012, p. 20) revela que "os primeiros sintomas manifestam-se, antes dos 3 anos de idade, o que faz com que os profissionais da saúde busquem incessantemente o diagnóstico precoce". Sobre isso, Cunha (2018, p. 23) afirma que quanto a obtenção de um diagnóstico precoce é o primeiro grande instrumento da educação. Cunha compreende que esse diagnóstico torna o papel professor como sendo fundamental, na medida em que é na idade escolar, que ocorre e se identifica socialização das crianças, período em que favorece a percepção das singularidades comportamentais.

Persp. Online: hum \& sociais aplicada., Campos dos Goytacazes, 30 (11)38-50- 2021 seer.perspectivasonline.com.br 
Ainda sobre a importância de se obter um diagnóstico precoce, Teixeira (2016, p. 5859) ressalta que "a demora na identificação dos sintomas, atraso no diagnóstico e tratamento reduz as chances de promover melhora no paciente, levando em conta de que no tratamento do TEA temos as "janelas da oportunidade"”.

Pesquisas recentes apontam que há uma relação dos aspectos biológicos nos casos de TEA. Silva (2012, p.180), contribui com algumas informações sobre as alterações nas seguintes áreas cerebrais: "sistema límbico, corpo caloso, gânglios da base, tálamo, cerebelo, substância branca e região frontotemporal".

A etiologia do autismo parece ser complexa e multifatorial, alertam Almeida e Wajnsztejn (2017, p.192-195), que acrescentam que "evidências acumuladas têm sugerido desequilíbrio em vários sistemas neuroquímicos, primariamente o dopaminérgico e $\mathrm{o}$ serotoninérgico".

O TEA agrupa uma série de comportamentos que compõem a díade: isolamento social, evitação de contato visual, inflexibilidade na rotina, hipersensibilidade ou hipersensibilidade sensorial, seguintes características comportamentais, usar pessoas como instrumentos para alcançar um objetivo, repúdio a contato físico, incompreensão dos sentimentos de outras pessoas, ecolalia tardia ou imediata, compreensão de linguagem metafórica, birras, fuga do olhar, dificuldade de generalização entre outros.

A literatura apresenta, ainda, algumas teorias que buscam explicar o funcionamento cerebral de pessoas com TEA. São elas:

- Teoria da Mente: sujeitos com autismo têm dificuldade de perceber mensagens subliminares comportamentais, por exemplo, não entendem que se alguém olha muito para o relógio é porque está com pressa. Da mesma forma, não consegue captar emoções: tristeza, alegria, aborrecimento no outro, bem como, brincadeiras maliciosas;

- Teoria dos Neurônios-espelho: as pessoas com autismo têm uma redução na ativação dos neurônios-espelho, ou seja, a prática de imitar ou praticar uma mesma ação de outra pessoa, não ocorre.

- Teoria da Coerência Central: apresentam limitações para generalizar, ver o todo, fixam-se em detalhes.

Frith e Happé (1994 apud WHITMAN, 2015, p. 108) acreditam que pessoas com TEA apresentam "anormalidade no processamento de informações, mais especificamente uma falha no processamento holístico ou o que chamam de "fraca coerência central"'.

Neste artigo, relatar-se-á o estudo de caso realizado com uma criança com hipótese diagnóstica de TEA; inicialmente, com diagnóstico psicopedagógico confirmado ao final dos atendimentos a partir da observação clínica, entrevistas de anamnese e para o professor, testes e escalas de avaliação.

\section{METODOLOGIA}

Este estudo e investigação quando a abordagem tem um enfoque qualidativo. Quanto aos objetivos é de natureza exploratória e descritiva. Os procedimentos técnicos utilizados foram a revisão de literatura e estudo de caso.

Persp. Online: hum \& sociais aplicada., Campos dos Goytacazes, 30 (11)38-50- 2021 
O estudo de caso foi realizado com uma criança do sexo feminino, de 3 anos, 10 meses e 7 dias, que estuda na Educação Infantil - Pré I, de uma escola pública do município de Campos dos Goytacazes - RJ. A professora a encaminhou para a orientação pedagógica com queixas de linguagem restrita, dificuldade de interação com os seus pares e ausência de foco atencional, permanecendo poucos minutos em cada proposta.

A primeira entrevista para observação clínica deu-se no espaço escolar, no dia 5/04/2019. A mãe relatou que a filha fala pouco em comparação com outras crianças. A gravidez foi desejada, nada ocorreu de diferente neste período. A criança nasceu com 41 semanas, $59 \mathrm{~cm}$. Logo que nasceu não chorou, mas depois sim.

A criança se sentou com um (1) ano, ficou em pé com quase dois (2) anos e andou com essa idade. Não tinha tendência a cair, machucar-se e golpear-se. Observa-se que possui dificuldades em manipular objetos, segura muito na ponta dos dedos. Apresenta importante atraso na linguagem, "foge o olhar, nem sempre olha nos olhos".

Desfraldou aos 3 anos e 7 meses; falou as primeiras palavras aos dois (2) anos. Teve problemas na fala, com vocabulário restrito e sem interação. Desde sempre demonstrava essa dificuldade. A mãe reforçou que tentou estimular, algumas vezes dá respostas, a questão é a dificuldade de estabelecer e manter um diálogo.

Iniciou a interação com a mãe antes de um (1) ano, o mesmo com o pai. Nunca foi de "estranhar" outras pessoas, pega na mão, vai ao colo. A criança não tem amigos, pela dificuldade em interagir. O que mais gosta de fazer é ver DVD, ouvir músicas, jogar bola, brincar de cavalinho pula, pula; desenhar (rabiscos) e encaixar números.

Em relação a doenças: não manifestou nenhuma, não operou, não teve traumatismos ou quedas, desmaios nem ausências, nenhuma doença atual, nem utiliza medicação. Observase apenas uma sinusite frequente, com acúmulo de secreção. Não realizou nenhum tipo de tratamento anterior e nem atual. Em relação a patologias dos antecedentes familiares, comentou que a avó da criança tem pressão alta e oorreram casos de AVC e câncer na família.

Está frequentando a escola pela primeira vez, apresentando dificuldades de relacionamento e interação. Argumenta que deseja contribuir para o desenvolvimento da filha.

\section{RESULTADOS E DISCUSSÃO}

O caso em questão relaciona-se a uma criança de três anos, dez meses e sete dias, que iniciou o processo diagnóstico com atendimento em consultório psicopedagógico, de abril a dezembro de 2019 para investigação da hipótese de transtorno do espectro autista, visto que as dificuldades relatadas estavam interferindo em seu desenvolvimento cognitivo e comportamental: participação em aula, interação com os seus pares, ausência de vínculos, linguagem restrita e prejuízos na atenção, que caracterizaram a suspeita de TEA.

Almeida e Wajnsztejn (2017, p. 189) argumentam que o autismo apresenta "um amplo espectro de manifestações clínicas, caracterizado por prejuízos na interação social, na comunicação verbal e não verbal e padrões restritos, repetitivos, estereotipados do comportamento, de interesses e atividades".

$\mathrm{O}$ primeiro passo foi iniciar a intervenção, mesmo sem diagnóstico. $\mathrm{Na}$ estimulação, todas as respostas funcionais ou disfuncionais, passaram a ser material de

Persp. Online: hum \& sociais aplicada., Campos dos Goytacazes, 30 (11)38-50- 2021

seer.perspectivasonline.com.br 
análise e observação clínica, de forma que, o processo de intervenção fosse também um processo de avaliação. Nessa perspectiva, Bossa $(2019$, p. 38) afirma que "o diagnóstico psicopedagógico é um processo, que se inicia na intervenção, em uma atitude investigadora que prossegue durante o trabalho, objetivando a observação e $o$ acompanhamento da evolução do sujeito".

Durante os atendimentos, priorizou-se a estimulação dos seus pontos frágeis, partindo dos seus interesses como a música e desenhos animados: seus hiperfocos (interesses restritos), como forma de interação e desenvolvimento cognitivo, comportamental, estruturação da linguagem, pensamento e comunicação. Cunha (2018, p. 25), reforça essa ideia de que é preciso num primeiro momento "conhecer o aluno, seus afetos e interesses, o que possibilitará a instituição de exercícios, atividades e afazeres que ajudarão a canalizar sua atenção".

No dia-a-dia dos encontros, alguns aspectos foram observados: a comunicação oral não tinha sentido, repetia sons aleatórios, trechos de diálogos (ecolalia tardia e imediata), prosódia diferenciada com marcação alongada nas vogais finais das palavras; manifestou não gostar da textura porosa da massinha de modelar, se retraiu com barulhos colocando os dedos

nos ouvidos e falando alto: "Não!" ou “Que não!" (Quer não), fugindo com o olhar, se jogando no chão; dificuldade para pular; imitação atrasada de movimentos corporais realizados em sessões anteriores; ausência de função ao brincar; usava o adulto como instrumento.

Por algumas vezes, organizou os brinquedos em coleção, por cor ou formato (Figura 3); demonstrava pouca atenção e foco nas tarefas, instabilidade nas brincadeiras e falta de interesse em algo específico. O movimento era sempre mexer em tudo e não brincar com nada. Em duas sessões teve momentos de desregulação, uma delas pela troca de sala.

A paciente começou a gritar, a jogar o puzzle para cima, ficou na ponta dos pés, tapou os ouvidos com os dedos indicadores e ficou rodando na sala. A mãe foi convidada a entrar, tentamos acalmar a criança, sem sucesso.

Nos atendimentos era um desafio o foco na proposta. A criança jogava materiais no tapete, espalhava, dispersava sem ter outros interesses; o que ficava no chão era pisoteado; andava pela sala sem objetivo, tentava abrir o armário, retirava todos os materiais das sacolas.

Neste contexto, é importante ressaltar que esta visão aprofundada das reações comportamentais e cognitivas da criança, são informações fundamentais e devem ser consideradas no processo diagnóstico. Salienta-se que o diagnóstico de TEA é essencialmente clínico e, por esse motivo, tudo que o sujeito faz, diz e deixa como resposta às estimulações, é material de investigação para os profissionais de educação e saúde que fazem parte desse processo.

Em todas as sessões de intervenção, foram utilizados jogos e atividades lúdicas, voltadas para a construção da função aos objetos; se trabalhava noções topológicas; a representação familiar com fantoches. 
A Hora do Jogo é priorizada na Psicopedagogia como um universo de possibilidades. Fernández (1991, p. 165), afirma que "não pode haver construção do saber, se não se joga com o conhecimento". O espaço do jogar é um espaço que gera confiança, criatividade, construção singular, é uma maneira de resgatar o prazer do conhecer e oportunizar novas aprendizagens.

No processo de intervenção e avaliação, a criança expressou um bom desenvolvimento cognitivo e respondeu positivamente aos estímulos.

Rotta (2016, p. 469), argumenta que "a aprendizagem é definida como modificações do SNC, mais ou menos permanentes, quando o indivíduo é submetido a estímulos e/ou experiências de vida, que serão traduzidas em modificações cerebrais", corroborando com a ideia de que a neuroplasticidade é a forma pela qual o sujeito aprende. A plasticidade cerebral leva à construção de novos conhecimentos e contribui para uma reorganização cerebral.

A paciente, neste período de atendimento, apresentou evolução ao nível de atenção compartilhada, observada na interação ocorrida na área de lazer do shopping, no momento em que a terapeuta aponta a bola azul que estava atrás da criança e ela se volta ao objeto no apontar locativo; passou a demonstrar maior tempo de atenção visual a um objeto que está sendo manipulado; reage a comandos de colocar objetos em locais solicitados no jogo simbólico, por exemplo: "vamos colocar as bolinhas dentro da geladeira, dentro do armário, dentro da gaveta" e "abrir e fechar as portas do armário" (de brinquedo); também evoluiu no olhar conjunto e recíproco na manipulação de objetos, reagindo a eles com sorrisos e expressões de surpresa, como ocorreu ao ter a percepção tátil e visual de bolinhas bem pequenas de isopor, que eram retiradas do recipiente e se espalhavam no limite da sala de atendimento. Também pede ajuda para abrir um objeto, mostrando e dizendo: "Abi" (abre); expressa carinho corporalmente, atendendo ao pedido de um beijo e respondendo ao "tchau"; desfruta da interação e direciona o olhar para o adulto e para a proposta por mais tempo; realiza a imitação de sons emitidos por animais; o sorriso social estava emergente, explicitando reações de achar graça de situações, por exemplo, quando interagia com a "dentadura de brinquedo" comendo as bolinhas gelatinosas que estavam em suas mãos. Nesse sentido, concordamos com Relvas (2012, p. 118) ao afirmar que "a cada nova vivência,experiência e aprendizado, novas conexões neurais são acrescentadas.

Como as propostas eram basedas em seus interesses (músicas e histórias infantis cantadas), a partir delas, conseguia-se explorar suas funções cognitivas e executivas. Embora o processo de intervenção fosse semanal, ainda havia muito a evoluir no quesito linguagem pragmática, condição básica para a comunicação entre os pares e pessoas do seu entorno social e familiar.

Observou-se que a paciente apresenta desenvolvimento cognitivo com base em suas respostas funcionais quanto ao domínio de reconhecimento de cores, numerais, letras do alfabeto.

O DSM-5 (2015, p. 56), aponta como sinal de bom prognóstico no autismo a "ausência de déficit intelectual e o não comprometimento da linguagem". Neste estudo de caso, a criança possui a cognição preservada, mas necessita de acompanhamento fonoaudiológico para evolução da linguagem expressiva. A intervenção psicopedagógica é indicada, para maior evolução nas áreas frágeis que afetam a aprendizagem.

Persp. Online: hum \& sociais aplicada., Campos dos Goytacazes, 30 (11)38-50- 2021 seer.perspectivasonline.com.br 


\section{Intervenções externas}

Destaca-se dois momentos bastante marcantes do atendimento clínico, as duas intervenções realizadas extra consultório: a primeira no Shopping 28 e a segunda no Hortigil Hortifrutti. A iniciativa de realizar uma intervenção extra consultório, teve como objetivos a quebra de rotina, para avaliar a flexibilização da criança; observar seu comportamento social; identificar a capacidade de adaptação e experimentar novas sensações e percepções.

No Shopping 28, foram vivenciados momentos de estimulação num ambiente amplo e diferenciado. A criança preferiu iniciar pela piscina de bolas e seguiu o caminho pelo túnel. Mergulhou, gritou, falou do seu jeito, jogou bolas à medida que solicitávamos a cor. Quando

cansou, atravessou novamente o túnel, seguindo o som do chocalho. No local havia barulho de música, bastante estímulo visual, mas nada a incomodou.

No ambiente, explorou as bonecas, entrou na casinha, andou de carrinho. Com os materiais do consultório, foram propostos pareamento de cores, com conflito cognitivo, oferecendo uma cor de bola que não correspondia a nenhum copo e as respostas foram funcionais. Neste dia também se verificou uma atitude de atenção compartilhada quando solicitada a pegar uma bolinha azul que estava atrás dela. A criança respondeu olhando para a bola e pegando.

O instrumento para a Intervenção Externa no Hortigil Hortifrutti, foi um material plastificado contendo os elementos da Música "A sopa do neném” _ Palavra Cantada. A intervenção teve como objetivos: oportunizar a socialização; modificar a rotina; comparar os alimentos que aparecem na história e os reais (cheirar, tocar, ver, comer); expandir os espaços de trabalho clínico; revisar a história de forma real e contextualizada; distinguir elementos comestíveis e não comestíveis da história; explorar o espaço do hortifrutti como espaço de aprendizagem; categorizar os alimentos; ampliar o vocabulário; estimular a mãe a fazer a sopa do neném em casa.

O espaço foi explorado em busca dos elementos da história, comparando a imagem ao alimento real. A criança cheirava e tocava, enquanto cantarolava a música. Tantas habilidades foram trabalhadas, desde os processos de atenção, memória organização espacial, a expressão da subjetividade, tudo através do campo musical.

\section{Dos Instrumentos e Escalas de Avaliação}

M-CHAT - Modified Checklist for Autism in Toddles (Lista Modificada para Autismo e Crianças Pequenas). É uma escala de rastreamento que avalia o comportamento da criança a partir de 18 meses. Afirma Teixeira (2016, p. 54), que esta escala tem o "objetivo de identificar traços de autismo em crianças de idade precoce". Deve ser aplicada nos pais ou cuidadores da criança, sendo autoaplicável e simples”.

O instrumento não revelou os itens críticos para o comportamento com hipótese de autismo. Creio que, talvez a mãe não tenha observado ou não reconheça os sinais aparentes do transtorno, pois se observa que quando a criança faz ecolalia, ela comenta que a filha está atenta ao que conversamos, não percebendo uma repetição a uma fala do adulto. Dentre os itens avaliados no instrumento, a mãe ressalta que a criança não usa o

Persp. Online: hum \& sociais aplicada., Campos dos Goytacazes, 30 (11)38-50- 2021 seer.perspectivasonline.com.br 
indicador para apontar ou pedir alguma coisa e também se mostra hipersensível a barulhos/ruídos chegando a tapar os ouvidos, que demonstram 2 falhas não críticas, mas apontam para dois sinais que caracterizam TEA. As respostas não fecham o score de três (3) falhas que justificam os traços autísticos.

CARS - Childhood Autism Rating Scale (Escala de Avaliação do Autismo na Infância) "é uma escala com 15 itens que auxiliam no diagnóstico e na identificação de crianças com autismo, além de ser sensível na distinção entre o autismo e outros atrasos no desenvolvimento" (TEIXEIRA, 2016, p. 53).

Tabela 1 - Escala de Avaliação do Autismo da Infância. Fonte: Pesquisa de campo.

\section{Resultado por Item}

\begin{tabular}{c|c|c|c|c|c|c|c|c|c|c|c|c|c|c|c}
\hline 2 & 2,5 & 2,5 & 2, & 2 & 1,5 & 2 & 1,5 & 1,5 & 2 & 3,5 & 2,5 & 2 & 1,5 & 3 & 32,5 \\
\hline 1 & 2 & 3 & 4 & 5 & 6 & 7 & 8 & 9 & 10 & 11 & 12 & 13 & 14 & 15 & $\begin{array}{c}\text { Tota } \\
\text { I }\end{array}$ \\
\hline
\end{tabular}

Fonte: Pesquisa de campo.

\section{Resultado Final}

\begin{tabular}{l|c}
\hline Normal: $15-29,5$ & \\
\hline Autismo leve/moderado: $30-36,5$ & $X$ \\
\hline Autismo grave: acima 37 & \\
\hline
\end{tabular}

Fonte: Pesquisa de campo.

De acordo com a Escala CARS, a paciente pontuou 32,5, caracterizando TEA leve - a criança apresenta somente um pequeno número de sintomas ou sintoma grau leve de autismo.

$$
\begin{aligned}
& 15-30 \text { - Sem autismo; } \\
& 30-36 \text { - Autismo Leve; } \\
& 36-60 \text { - Autismo grave }
\end{aligned}
$$


$\mathrm{Na}$ escala CARS, a criança foi avaliada em 15 habilidades, são elas: relacionamento interpessoal, imitação, resposta emocional, expressão corporal, uso do objeto, adaptação a mudanças, uso do olhar, uso da audição; uso do paladar, olfato e tato; medo e nervosismo, comunicação verbal, comunicação não verbal, atividade, grau e consistência das respostas da inteligência.

As pontuações são lançadas de acordo com a manifestação de sinais e sintomas, somando-se o score de cada item: o número inteiro representa o posicionamento qualitativo do item especificado e, cada meio ponto $(0,5)$, a criança situa-se no nível intermediário. Somando-se toda pontuação, temos as o resultado do grau do TEA.

\section{CONSIDERAÇÕES FINAIS}

No período de intervenção, a criança respondeu positivamente aos estímulos, atestando o conceito de neuroplasticidade neste período de 'janela das oportunidades'. Apresenta a cognição preservada, conhece números e todas as letras do alfabeto. Realiza a escrita de letra, se partir da experiência corporal; inicia a apropriação fonológica e apresenta boa motricidade fina.

Expressa desenvolvimento emergente em diversas áreas e habilidades: imitação; respostas a gestos; aceita aproximação, carinho, corresponde ao aceno, abraça e beija. Demonstra alegria e o sorriso social começa a emergir; consegue manter a atenção compartilhada e conjunta em relação a um objeto; o tempo de concentração está mais ampliado; inicia o processo de dar funcionalidade a objetos e completa cantarolando, partes de música.

A partir da observação clínica em consultório, da Entrevista de Anamnese, da Escala de avaliação do comportamento infantil para o professor, da Escala M-CHAT e a Escala CARS, a criança apresentou perfil compatível com TEA leve, que de acordo com o DSM-5 (2015, p. 52) nível 1, "exigindo apoio" substancial na díade comunicação social comportamentos restritos e repetitivos. Apresenta interesses restritos, déficit na comunicação social e linguagem pragmática. Há presença de cognição preservada, com possibilidades evolutivas da aprendizagem.

Pode-se, perceber portanto, avanços significativos em termos comportamentais e linguísticos; a criança tem potencial cognitivo para evoluir. Ressalta-se, no entanto, que a continuidade nas terapias é imprescindível para suscitar ganhos, com a possibilidade de ter os sintomas amplamente revertidos.

\section{REFERÊNCIAS}

ALMEIDA, D. P. A.; WAJNSZTEJN, R. Transtorno do Espectro Autista. In: WAJNSZTEJN: A. C.; WAJNSZTEJN, R. Dificuldades escolares: um desafio superável. 3 ed. São Paulo: Pampaideia, 2017, p. 192-195.

AMARAL, A.; OHY, J. Jogos cognitivos: um olhar multidisciplinar. Rio de Janeiro: Wak, 2018.

AMERICAN PSYCHIATRIC ASSOCIATION (APA). Manual de diagnóstico e estatístico de transtornos mentais: DSM-5. Porto Alegre: Artmed, 2014. p. 50-59.

Persp. Online: hum \& sociais aplicada., Campos dos Goytacazes, 30 (11)38-50- 2021

seer.perspectivasonline.com.br 
BOSSA, Nadia A. A Psicopedagogia no Brasil: contribuições a partir da prática. 5 ed. Rio de Janeiro: Wak, 2919.

CALOMENI, M. R.; PELLICIARI, B. C.; ARÊAS NETO, N. T.; MARTINS DANTAS, E. H.; SILVA, V. F; Treinamento mental e estimulação cerebral: efeitos na memória de trabalho de crianças com dificuldade de aprendizagem. Perspectivas Online: Humanas \& Sociais Aplicadas, v. 8, n. 22, 2018. Disponível em: https://ojs3.perspectivasonline.com.br/humanas_sociais_e_aplicadas/article/view/1214/104 . Acesso em: 20 nov. 2020.

COSENZA; R. M.; GUERRA, L. B. Neurociência e educação: como o cérebro aprende. Porto Alegre: Artmed, 2011.

CUNHA, E. Autismo e inclusão: psicopedagogia e práticas educativas na escola e na família. 7 ed. Rio de Janeiro: Wak, 2017.

CUNHA, E. Autismo na escola: um jeito diferente de aprender, um jeito diferente de ensinar. Rio de Janeiro: Wak, 2018.

DIAS, F. M.A.; PESSANHA, R. G. B.; NICOLARU, C. C. B. A. A inter-relação entre memória e aprendizagem. Perspectivas Online: Humanas \& Sociais Aplicadas, v. 8, n. 21, 2018. Disponível em: https://ojs3.perspectivasonline.com.br/humanas_sociais _e_aplicadas/article/view/1345/1010. Acesso em: 20 nov. 2020.

FERNÁNDEZ, Alicia. A inteligência aprisionada: abordagem psicopedagógica clínica da criança e sua família. Porto Alegre: Artes Médicas, 1991.

RELVAS, M. P. Neurociência e transtornos de aprendizagem: as múltiplas eficiências para uma educação inclusiva. 6. ed. Rio de Janeiro: Wak, 2015.

RELVAS, M. P. Que cérebro é esse que chegou à escola? as bases neurocientíficas da aprendizagem. 3. ed. Rio de Janeiro: Wak, 2017.

RELVAS, M. P. Sob o comando do cérebro: entenda como a neurociência está no seu dia a dia. Rio de Janeiro: Wak, 2014.

ROTTA, N. T.; OHLWLWEILER, L.; RIESGO, R. S. Transtornos da aprendizagem: abordagem neurobiológica e multidisciplinar. 2. ed. Porto Alegre: Artmed, 2016.

TEIXEIRA, G. Manual do Autismo. 2. ed. Rio de Janeiro: BestSeller, 2016.

WHITMAN. T. L. O. Desenvolvimento do autismo: social, cognitivo, linguístico, sensóriomotor e perspectivas biológicas. São Paulo: M. Books do Brasil, 2015. 